\title{
Isolated Sixth Nerve Palsy as a First Presentation of Nasopharyngeal Carcinoma: A Case Series
}

\author{
Apatsa Lekskul (iD \\ Supanat Thanomteeranant (iD) \\ Phantaraporn Tangtammaruk (D) \\ Wadakarn Wuthisiri \\ Department of Ophthalmology, \\ Ramathibodi Hospital, Mahidol \\ University, Bangkok, Thailand
}

Correspondence: Wadakarn Wuthisiri Department of Ophthalmology, Ramathibodi Hospital, Mahidol University, 270 Rama 6 Road, Thung Phayathai

Subdistrict, Ratchathewi District,

Bangkok, 10400, Thailand

Tel +66 6I 1947887

Fax +6622011516

Email wuthisiri@gmail.com
Purpose: To describe isolated sixth nerve palsy as an uncommon presentation of nasopharyngeal carcinoma (NPC).

Patients and Methods: We analyzed the demographics, clinical presentation, neuroimaging findings, and pathological examination results of the nasopharyngeal masses of patients diagnosed with isolated sixth nerve palsy due to NPC.

Results: Isolated sixth nerve palsy as the first presenting sign of NPC was diagnosed in five patients. Two patients were aged $<50$ years and three were aged $>50$ years, and one of these three older patients had vascular risk factors. Most of the patients in our case study had an uncommon presentation of isolated sixth nerve palsy with diplopia, followed by typical NPC signs such as a neck lump (two patients), nasal obstruction (two patients), tinnitus (two patients), hearing loss (one patient), and epistaxis (one patient). Pathological examination revealed non-keratinizing NPC in all cases. Neuroimaging showed that the sites of tumor invasion were the clivus, Dorello's canal, and cavernous sinus, which explained the sixth nerve palsy. One patient whose NPC had progressed to the orbital apex later developed other cranial nerve palsies. Three patients underwent concurrent chemoradiotherapy (CCRT), and one patient underwent CCRT with adjuvant chemotherapy. The last patient was unfortunately lost to follow-up. The symptoms of four patients who underwent treatment improved.

Conclusion: Isolated sixth nerve palsy can be the first presentation of NPC, especially in patients aged $<50$ years old without microvascular risk factors or even in patients aged $>50$ years old with microvascular risk factors. This case study emphasizes that a thorough clinical history and careful physical and neuroimaging examinations might be necessary to rule out life-threatening conditions in patients with isolated sixth nerve palsy.

Keywords: diplopia, abducens nerve, paralytic strabismus, neck mass

\section{Introduction}

Nasopharyngeal carcinoma (NPC) is a rare disease worldwide. Nevertheless, it shows a high prevalence in Southern China, Hong Kong, and Southeast Asia. ${ }^{1,2}$ Data from Worldwide distribution of commonly reported NPC in 2018, ${ }^{3,4}$ estimated number of new cases for China, Indonesia, and Thailand were 47.7\%, 14.2 and $1.7 \%$, respectively. The incidence was characterized by geographical global distribution with an age-standardized rate of about 3.0 per 100,000 in China to 0.4 per 100,000 in white populations. ${ }^{3,4}$ In the Thai population, the male:female ratio has been reported as 3.7:1.2 patients per 100,000 per year. ${ }^{5}$ Patients with NPC usually present with neck lumps $(60.3 \%)$, blood in the saliva $(41.3 \%)$, hearing loss $(30.2 \%)$, epistaxis $(23.1 \%)$, nasal obstruction $(17.2 \%)$, tinnitus $(13.7 \%)$ and cranial nerve palsy $(9.4 \%){ }^{6}$ Although all cranial nerves can be involved in NPC, cranial 
nerves V, VI, VIII, and XII are most commonly affected at the same time as or separately from the presenting signs of $\mathrm{NPC}^{7,8}$ Isolated unilateral sixth nerve palsy is a rare presentation of NPC, and only a few such cases have been reported in the literature. ${ }^{9}$ We herein report five cases of isolated sixth nerve palsy in patients with NPC in Ramathibodi Hospital. The demographic data, clinical features, investigation, and management of these cases are summarized in Table 1.

\section{Patients and Methods}

A retrospective case series of patients with isolated sixth nerve palsy and NPC were reviewed from 1 January 2009 to 30 November 2020 at Ramathibodi Hospital. The study protocol was approved by the Human Research Ethics Committee Faculty of Medicine Ramathibodi Hospital, Mahidol University and adhered to the tenets of the Health Insurance Portability and Accountability Act and the Declaration of Helsinki. Written informed consent was obtained from all patients regarding their case details and accompanying images before the publication. The patients' demographic data, clinical presentation, neuroimaging, and pathological result of nasopharyngeal mass were studied. The main objective was to identify cases of isolated sixth nerve palsy in conjunction with NPC.

\section{Case I}

A 40-year-old woman presented with horizontal binocular diplopia that began a few weeks previously and worsened when looking at a distance. She also had a 2-month history of an intermittent right-sided headache, eye pain, right nasal obstruction, and tinnitus. The patient had no other symptoms associated in NPC. She also had no significant weight loss or head injury during this period. The patient was otherwise healthy, without a history of smoking or systemic diseases.

On examination, the best-corrected visual acuity (BCVA) was 20/20 in both eyes. There was no relative afferent pupillary defect (RAPD), the pupil size was equal and the anterior and posterior segment examinations were unremarkable in both eyes. There were no optic disc abnormalities such as papilledema or infiltrative optic neuropathy. Orthoptic examination revealed right esotropia of 4 prism diopters (PD) at distance and slight esotropia at near. The esotropia worsened with right gaze at which point the patient also developed diplopia although she did not have a compensated head turn. Ocular motility was normal in the left eye, but there was mild limitation in abduction in the right eye (able to abduct 90\%). Sensory testing in areas V1-V3 was intact. Rhinoscopy revealed an inflamed mass at the right nasopharynx, extending across the midline to the left nasopharynx. Pathological examination revealed non-keratinizing NPC. Axial orbital magnetic resonance imaging (MRI) was performed and the fat-saturated contrast-enhanced T1-weighted image (T1FS) showed an enhancing infiltrative lesion that involved the right sphenoid sinus, clivus, prepontine cistern, and right-side cavernous sinus. The lesion also caused moderate luminal narrowing of the right internal carotid artery (ICA) (Figure 1). These MRI findings explained the patient's limitation in abduction due to sixth nerve palsy.

She responded well to concurrent chemoradiotherapy (CCRT). Most of her symptoms such as horizontal diplopia significantly improved and the orthoptic examination revealed orthotropia with normal ocular motility.

\section{Case 2}

A 53-year-old man presented with a 2-month history of horizontal diplopia and eye pain. A review of his medical history revealed that he had had a neck mass for 10 months and runny nose and nasal obstruction for 3 months. He also had a right-sided headache, eye pain, right nasal obstruction, and tinnitus. He is a known smoker with approximately 20 pack-years history. However, he was otherwise healthy with no history of significant weight loss or head injury.

Ophthalmic examination showed a BCVA of 20/20 in the right eye and 20/25 in the left eye. Anterior segment and posterior segment examination were unremarkable in both eyes. There was no RAPD and the pupil size was equal in both eyes. Orthoptic examination revealed left esotropia of $45 \mathrm{PD}$ at distance and $50 \mathrm{PD}$ at near, and the esotropia worsened in the left gaze. Ocular motility was normal in the right eye but marked abduction deficit was present in the left eye (unable to move across midline). Cranial nerve areas V1-V3 were intact. Rhinoscopy revealed a mass at the left nasopharynx and subsequent pathological examination showed a non-keratinizing NPC. Axial brain MRI revealed that the mass involved the left cavernous sinus and encased the left cavernous ICA without definite luminal narrowing. It extended posterosuperiorly along the retroclival and bilateral petroclival regions with a pressure effect on the left side of the pons and partially encased the basilar artery (Figure 2A). Atrophy of the left lateral rectus muscle was also observed 
Table I Details of Cases of Isolated Sixth Nerve Palsy with Nasopharyngeal Carcinoma

\begin{tabular}{|c|c|c|c|c|c|}
\hline & Case I & Case 2 & Case 3 & Case 4 & Case 5 \\
\hline Age (years) & 40 & 53 & 67 & 57 & 42 \\
\hline Sex & Female & Male & Female & Male & Female \\
\hline $\begin{array}{l}\text { Underlying } \\
\text { diseases }\end{array}$ & - & - & $\begin{array}{c}\text { Diabetes mellitus and } \\
\text { dyslipidemia }\end{array}$ & - & - \\
\hline \multicolumn{6}{|c|}{ Clinical presentation } \\
\hline I. Diplopia & + & + & + & + & + \\
\hline $\begin{array}{l}\text { 2. Abnormal } \\
\text { head posture }\end{array}$ & - & - & - & - & + \\
\hline 3. Neck mass & - & + & - & + & - \\
\hline $\begin{array}{l}\text { 4. Associated } \\
\text { symptoms and } \\
\text { signs described } \\
\text { in main text }\end{array}$ & + & + & + & + & - \\
\hline \multicolumn{6}{|c|}{ Ocular examinations } \\
\hline $\begin{array}{l}\text { Best-corrected } \\
\text { visual acuity }\end{array}$ & $20 / 20,20 / 20$ & $20 / 20,20 / 25$ & $20 / 40,20 / 40$ & $20 / 25,20 / 25$ & $\begin{array}{c}20 / 25,20 / \\
25\end{array}$ \\
\hline \multicolumn{6}{|c|}{ Orthoptic examination } \\
\hline \multicolumn{6}{|c|}{ I. Prism cover test } \\
\hline - Distance & Right ET: 4 PD & Left ET: 45 PD & Right ET: 35 PD & Right ET: 30 PD & $\begin{array}{l}\text { Left ET: } \\
35 \text { PD }\end{array}$ \\
\hline - Near & Right ET': slight & Left ET': 50 PD & Right ET': 40 PD & Right ET': 40 PD & $\begin{array}{l}\text { Left ET': } \\
35 \text { PD }\end{array}$ \\
\hline \multirow[t]{2}{*}{ 2. EOM } & $\begin{array}{l}\text { Right eye } \\
\text { abduction } \\
\text { deficit } 90 \%\end{array}$ & Right eye full EOM & $\begin{array}{l}\text { Right eye abduction deficit } \\
0 \%\end{array}$ & $\begin{array}{l}\text { Right eye abduction deficit } \\
0 \%\end{array}$ & $\begin{array}{l}\text { Right eye } \\
\text { full EOM }\end{array}$ \\
\hline & $\begin{array}{l}\text { Left eye full } \\
\text { EOM }\end{array}$ & Left eye abduction deficit $0 \%$ & Left eye full EOM & Left eye full EOM & $\begin{array}{l}\text { Left eye } \\
\text { abduction } \\
\text { deficit 0\% }\end{array}$ \\
\hline $\begin{array}{l}\text { Diagnosis: } \\
\text { Pathological } \\
\text { report }\end{array}$ & \multicolumn{5}{|c|}{ Non-keratinizing nasopharyngeal carcinoma } \\
\hline Management & CCRT & $\begin{array}{l}\text { CCRT and adjuvant } \\
\text { chemotherapy }\end{array}$ & CCRT & CCRT & $\begin{array}{l}\text { Lost to } \\
\text { follow-up }\end{array}$ \\
\hline Progression & $\begin{array}{c}\text { Ocular } \\
\text { movement } \\
\text { within normal } \\
\text { limits in both } \\
\text { eyes }\end{array}$ & $\begin{array}{l}\text { Ocular movement within } \\
\text { normal limits in right eye but } \\
\text { abduction slightly deficient in } \\
\text { left eye }\end{array}$ & $\begin{array}{l}\text { Ocular movement within } \\
\text { normal limits in left eye but } \\
\text { abduction slightly deficient in } \\
\text { right eye }\end{array}$ & $\begin{array}{l}\text { Ocular movement within } \\
\text { normal limits in left eye but } \\
\text { abduction slightly deficient in } \\
\text { right eye }\end{array}$ & - \\
\hline
\end{tabular}

Notes: +Present; -Absent.

Abbreviations: ET, esotropia; PD, prism diopters; CCRT, concurrent chemoradiotherapy; EOM, extraocular movement. 


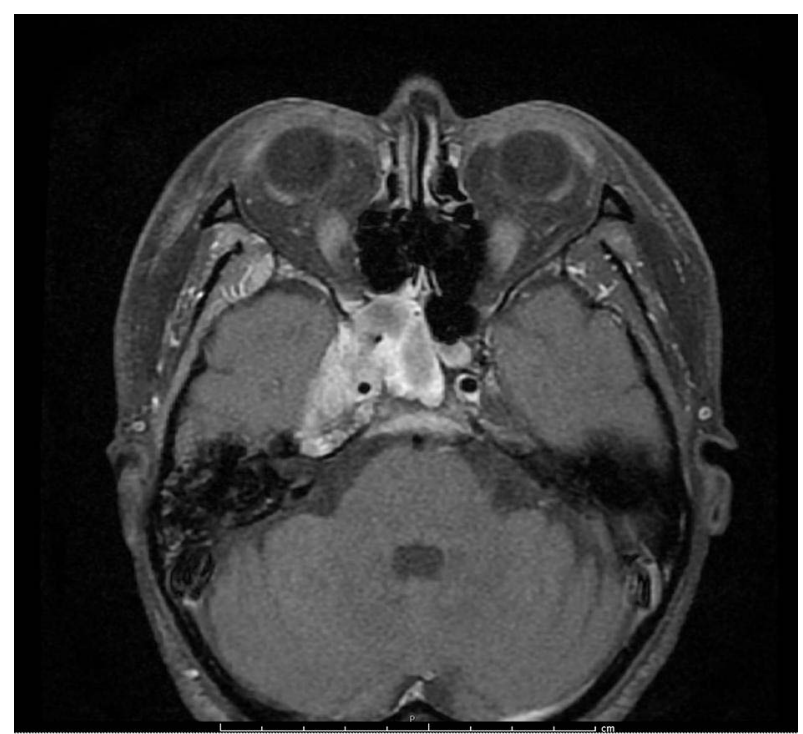

Figure I Axial orbital MRI (TIFS) showed that the enhancing infiltrative lesion involved the right sphenoid sinus, clivus, prepontine cistern, and right-side cavernous sinus. It also encapsulated the right ICA and caused moderate luminal narrowing.

(Figure 2B). The patient underwent CCRT and adjuvant chemotherapy. Two months after treatments the patient showed no symptoms such as horizontal diplopia, nasal obstruction, and runny nose. Orthoptic examination revealed improvement in his deviation (left esotropia of $25 \mathrm{PD}$ at distance and $14 \mathrm{PD}$ at near, which worsened in the left gaze). Ocular motility in the left eye markedly improved with the ability to abduct $80 \%$.

\section{Case 3}

A 67-year-old woman presented with a 3-week history of limited eye movement. She experienced horizontal binocular diplopia, hearing loss, and tinnitus but had no other symptoms associated with NPC. She had diabetes mellitus and dyslipidemia. She was a non-smoker and had no history of head trauma, significant weight loss, or eye surgery.

Ophthalmic examination showed a BCVA of 20/40 in both eyes. Anterior segment and posterior segment examinations were unremarkable. She had a normal pupillary response and the pupil size was equal in both eyes with absent RAPD. Orthoptic examination showed right esotropia of $35 \mathrm{PD}$ at distance and $40 \mathrm{PD}$ at near, which was worse in the right gaze. Ocular motility in the left eye was normal, while the right eye exhibited a marked abduction deficit (unable to cross the midline). The cranial nerve areas V1-V3 were intact. A mass was discovered at the right nasopharynx during rhinoscopy. Pathological examination revealed non-keratinizing NPC. Brain MRI showed an enhancing infiltrative mass that involved the entire nasopharynx, posterior nasal cavities, bilateral sphenoid sinuses, and skull base, including the right Dorello's canal, which affected the right sixth cranial nerve (Figure 3). Six months after completion of treatment, the patient experienced improvement of her symptoms: diplopia, hearing loss, and tinnitus. Orthoptic examination demonstrated right esotropia of $25 \mathrm{PD}$ at distance and 16 PD at near. The ocular motility in her right eye showed significant improvement (ability to abduct $60 \%$ ).

\section{Case 4}

A 57-year-old man presented with a 5-month history of horizontal binocular diplopia, after which he found a lump on the left side of his neck and developed epistaxis and
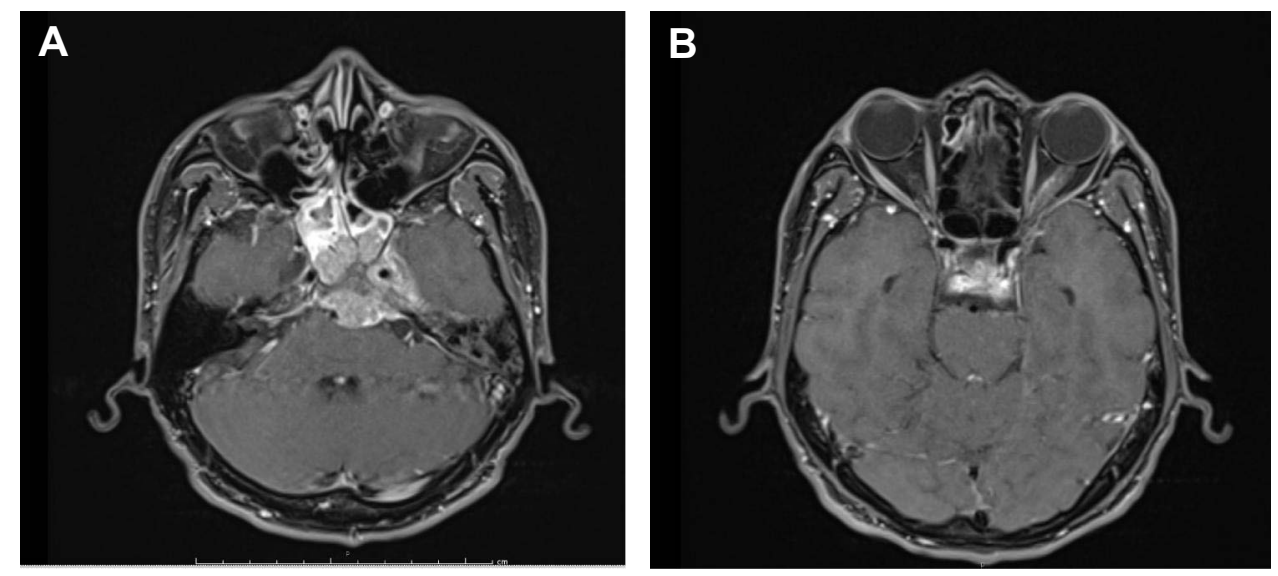

Figure 2 (A) Axial brain MRI (TIFS) showed that the mass involved the left cavernous sinus and encased the left cavernous ICA without definite luminal narrowing. It extended posterosuperiorly along the retroclival and bilateral petroclival regions with a pressure effect on the left side of the pons and partially encased the basilar artery. (B) Axial brain MRI (TIFS) showed atrophy of the left lateral rectus muscle (arrow). 


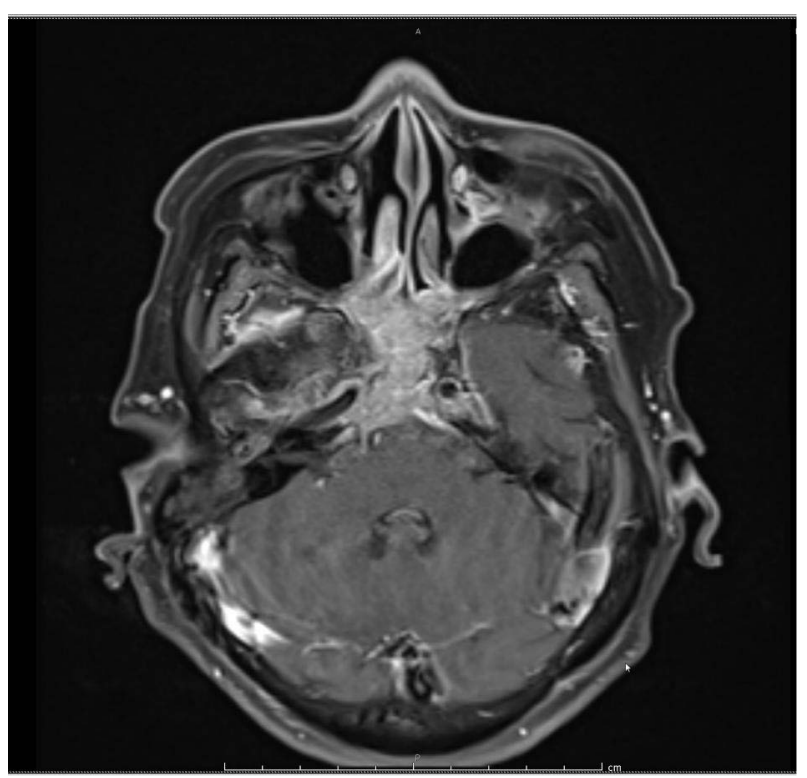

Figure 3 Axial brain MRI (TIFS) showed an enhancing infiltrative mass that involved the entire nasopharynx, posterior nasal cavities, bilateral sphenoid sinuses, and skull base, including the right Dorello's canal.

tinnitus. He had no headache, eye pain, nasal obstruction, or hyposmia. He had experienced no significant weight loss or brain injury during this period. He had no systemic diseases and no history of smoking.

Ophthalmic examination revealed a BCVA of 20/25 in both eyes. The anterior segment and posterior segment examination findings were normal. He had absent RAPD with normal pupillary responses and the pupil size was equal in both eyes. Orthoptic examination showed right esotropia of $30 \mathrm{PD}$ at distance and $40 \mathrm{PD}$ at near. The right esotropia and diplopia were worse in the right gaze. Ocular motility was normal in the left eye, but markedly limited abduction was noted in the right eye (unable to cross the midline). The cranial nerve areas V1-V3 were intact. Two weeks later the patient reported markedly blurred vision in his right eye. The ophthalmic examination showed a BCVA of hand motion in the right eye and 20/25 in the left eye. He developed grade III RAPD in the right eye. Posterior segment examination demonstrated a mildly pale optic disc in the right eye and normal optic disc in the left eye. Orthoptic examination revealed orthotropia in the primary position due to total ophthalmoplegia in the right eye and normal eye movement in the left eye. Sensation at V1-V3 distribution was reduced on the right side. Rhinoscopy showed a tumor in the right nasopharynx. Pathological examination revealed a non-keratinizing NPC. Postcontrast axial brain MRI showed an enhancing infiltrative mass that involved the right ethmoid and bilateral sphenoid sinuses with extension into the right orbit. The mass also encased the right cavernous ICA (Figure 4). The patient was treated with CCRT. Two months after treatment his symptoms of diplopia, epistaxis, and tinnitus significantly improved. Orthoptic examination demonstrated right esotropia of 16 PD at distance and $20 \mathrm{PD}$ at near. The ocular motility in his right eye showed marked improvement (ability to abduct $80 \%$ ).

\section{Case 5}

A 42-year-old woman presented with a 2-month history of dizziness and horizontal diplopia. She denied any symptoms of headache, visual loss, epistaxis, reduced hearing, tinnitus, or hyposmia, and she had experienced no significant weight loss or head injury during this period. The patient was otherwise healthy and had no history of smoking or systemic diseases.

Ophthalmic examination showed a BCVA of 20/25 in both eyes. Anterior segment and posterior segment examinations were unremarkable in both eyes. She had a normal pupillary response and the pupil size was equal in both eyes with absent RAPD. Orthoptic examination revealed left esotropia of 35 PD at distance and near, which worsened in the left gaze. The patient developed a left face turn to compensate for the limitation of abduction in the left eye. Ocular motility was within normal limits in the right eye, but a marked abduction deficit was present in the left eye (unable to move across the midline). Sensory testing in areas V1-V3 showed that both sides were intact. Rhinoscopy revealed a mass at the right nasopharynx, and a biopsy was performed. Pathological examination showed non-keratinizing NPC. Axial brain MRI showed a large enhancing mass at the left sphenoid sinus and petrous bone with involvement of the sixth cranial nerve (Figure 5A), and axial T2-weighted DRIVE MRI showed involvement of the left Dorello's canal (Figure 5B). Unfortunately, the patient did not return for follow-up.

\section{Discussion}

The most common cause of isolated sixth nerve palsy in patients over 50 years of age who have vascular risk factors is microvascular ischemia, which usually resolves within 3 months and may not require neuroimaging. ${ }^{10}$ However, other etiologies associated with serious consequences and neurological abnormalities cannot be excluded without neuroimaging, especially in patients under 50 years old who have no vascular risk 


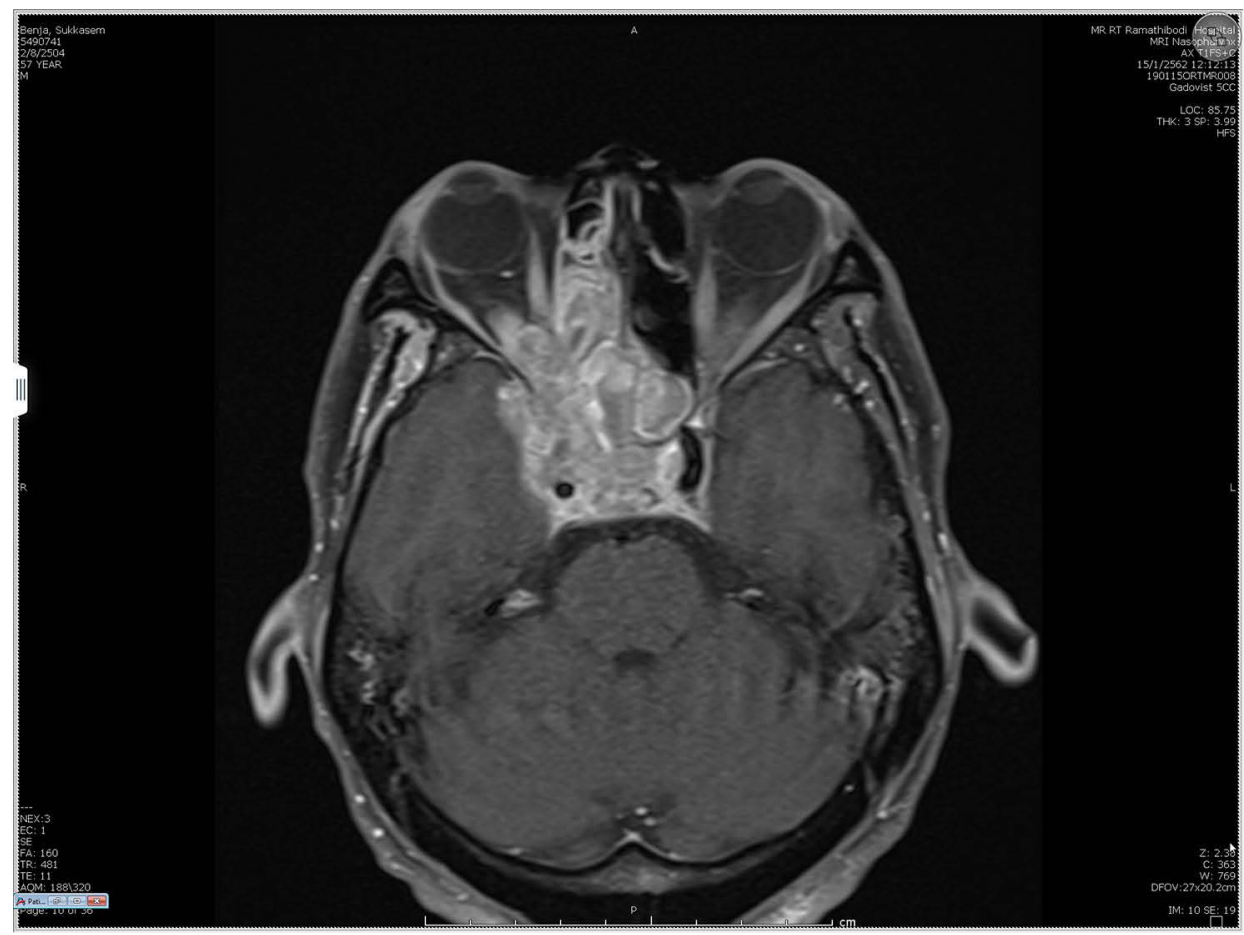

Figure 4 Axial brain MRI (TIFS) showed an enhancing infiltrative mass that involved the right ethmoid and bilateral sphenoid sinuses with extension into the right orbit. The mass also encased the right cavernous ICA.
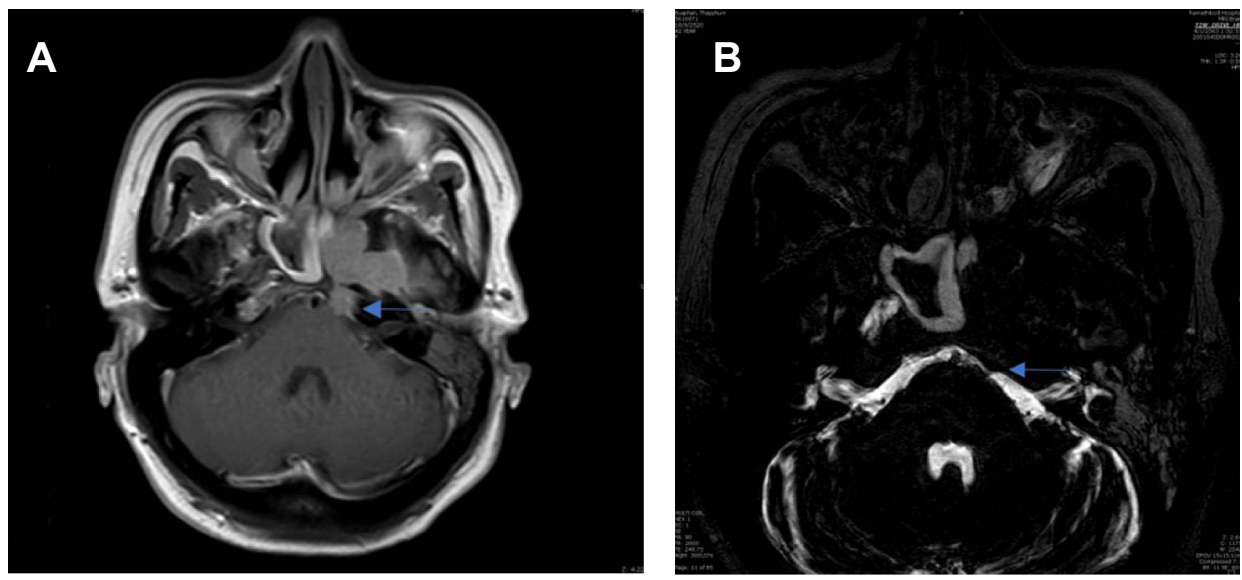

Figure 5 (A) Axial brain MRI (TIFS) showed a large enhancing mass at the left sphenoid sinus and petrous bone with involvement of the sixth cranial nerve. (B) Axial T2weighted DRIVE MRI showed involvement of the left Dorello's canal.

factors. ${ }^{10,11}$ The etiology of isolated sixth nerve palsy in patients aged 15 to 50 years, as reported by Moster et al, ${ }^{12}$ was vasculopathy in $29 \%$ of patients, a tumor in $16 \%$, multiple sclerosis in $12 \%$, presumed inflammation in $8 \%$, trauma in $6 \%$, and orbital amyloidosis in $2 \%$. Another study by Bendszus et $\mathrm{al}^{13}$ focusing on the MRI findings in patients with isolated sixth nerve palsy aged $<50$ years, showed that a lesion was identified on the initial MRI scan in about $63 \%$ of patients, and $49 \%$ of those patients had a tumor or tumor-like lesion. There are some differences in the etiologies of isolated sixth nerve palsy between population-based data and tertiary referral-based data. ${ }^{14}$ Patel et $\mathrm{al}^{14}$ performed a population-based study showing that up to $5 \%$ of cases of isolated sixth nerve palsy are caused by neoplasms in patients older than 50 years. A large series of tertiary referral-based data analyzed by Richards et $\mathrm{al}^{15}$ showed that $21 \%$ of cases of isolated sixth nerve palsy were associated with neoplasms. Because of the high 
incidence of NPC in Southeast Asian populations, ${ }^{1-4}$ including those of Thai ethnicity, clinicians should consider NPC as a possible etiology of isolated sixth nerve palsy in patients under 50 years of age in the absence of microvascular risk factors or non-traumatic sixth nerve palsy. In the present series, however, three patients with isolated sixth nerve palsy as the first presenting sign of NPC were older than 50 years, and one of these three patients had vascular risk factors. This finding emphasizes that isolated sixth nerve palsy in a patient older than 50 years with microvasculopathy risk factors can be caused by serious diseases such as NPC. In accordance with this, Chou et $\mathrm{al}^{16}$ found that more than $50 \%$ of patients with non-microvascular palsy had vasculopathic risk factors. High suspicion of serious disease with complete ophthalmic and systemic examination findings is crucial for deciding whether to perform neuroimaging.

NPC is a relatively rare disease in which the tumor may remain asymptomatic for several months. ${ }^{17}$ The presentations of NPC include a neck lump (metastasis to the cervical lymph nodes), blood-stained saliva or sputum, hearing loss, epistaxis, nasal obstruction, and tinnitus. ${ }^{6}$ In our case series, most patients had an atypical presentation of isolated sixth nerve palsy with diplopia, and then developed typical findings of a neck lump (2 patients), nasal obstruction (2 patients), tinnitus ( 2 patients), hearing loss (1 patient), and epistaxis (1 patient). A delayed diagnosis of NPC results in more severe disease. Early detection of isolated sixth nerve palsy and recognition that it could be caused by NPC is important for ophthalmologists to consider whether to refer patients to an otolaryngologist to check for NPC while awaiting neuroimaging. This strategy might help to achieve early detection and treatment of NPC.

At the time of diagnosis of NPC, cranial nerve involvement may be present in up to $20 \%$ of patients. ${ }^{7}$ The location of the nasopharynx, which lies beneath the base of the skull, allows for intracranial tumor invasion in patients with NPC. Cranial nerve involvement at the time of diagnosis indicates intracranial extension of NPC, which has a poor prognosis. ${ }^{11,18}$ The most commonly affected nerves are cranial nerves VI, V, and IX. Cranial nerves VI and V are usually affected simultaneously at the time of diagnosis. Isolated sixth nerve palsy at the time of diagnosis of NPC is uncommon. ${ }^{19}$ The sixth and fifth nerves were affected in one of our patients; however, involvement of the fifth nerve occurred later. The sixth nerve may be affected by various lesions at any level from the brain stem to the cavernous sinus and orbit. Batawi and Micieli $^{20}$ reported an NPC patient who presented with combination of sixth nerve palsy and ipsilateral Horner's syndrome. This presentation helps localization of NPC at the level of posterior cavernous sinus. Neuroimaging is important to assess the location and extension of these lesions. Previous studies have demonstrated NPC lesions associated with isolated sixth nerve palsy. For instance, Aghdam et al ${ }^{18}$ described expansion of a mass into the middle cerebral fossa, affecting the clivus. Additionally, Baharudin et $\mathrm{al}^{9}$ reported that a brain computed tomography scan revealed an enhancing parasellar lesion that extended to the clivus, causing sixth nerve palsy. In our series, neuroimaging revealed the location of tumor invasion in each case, including the clivus, Dorello's canal, cavernous sinus, and orbital apex, thus explaining the isolated sixth nerve palsy. One patient in our series, in whom the NPC had extended to the orbital apex, eventually acquired other cranial nerve palsies.

Cranial nerve involvement in NPC is not rare, but isolated sixth nerve palsy is uncommon. Neuroimaging is essential in patients with atypical characteristics.

To the best of our knowledge, this is one of the largest case series to date on the clinical presentation, characteristics, and investigation of isolated sixth nerve palsy as a presentation of NPC. However, this study had several limitations. First, this study was retrospective in nature. The protocols for obtaining relevant information were not identical in all patients. Second, there was possible bias in the patient selection of this study. All patients in our case series were recruited from a tertiary referral center. This may have increased the overall prevalence of this rare disease. Third, all patients were Thai; thus, direct application of our findings to patients of other ethnicities should be performed with caution.

\section{Conclusion}

Microvascular infarction is the most common cause of isolated sixth nerve palsy in people over 50 years of age; however, atypical presentations should be explored. New onset of diplopia or other symptoms of cranial nerve palsy should be evaluated further to rule out any life-threatening conditions, and NPC should be considered. A thorough clinical history and neuroimaging examinations are necessary. A neuroimaging assessment of the clivus, Dorello's canal, and cavernous sinus should be conducted when a patient has isolated sixth nerve palsy with NPC.

Any isolated nerve palsy warrants neuroimaging with use of contrast in younger patients with or without systemic illness and in older patients with no systemic illness. 


\section{Disclosure}

The authors report no conflicts of interest in this work.

\section{References}

1. Devi BC, Pisani P, Tang TS, Parkin DM. High incidence of nasopharyngeal carcinoma in native people of Sarawak, Borneo Island. Cancer Epidemiol Biomarkers Prev. 2004;13(3):482-486.

2. Chang ET, Ye W, Zeng YX, Adami HO. The evolving epidemiology of nasopharyngeal carcinoma. Cancer Epidemiol Biomarkers Prev. 2021;30(6):1035-1047. doi:10.1158/1055-9965.EPI-20-1702

3. Bray F, Ferlay J, Soerjomataram I, Siegel RL, Torre LA, Jemal A. Global cancer statistics 2018: GLOBOCAN estimates of incidence and mortality worldwide for 36 cancers in 185 countries. CA Cancer J Clin. 2018;68(6):394-424. doi:10.3322/caac.21492

4. Fu ZT, Guo XL, Zhang SW, et al. [Incidence and mortality of nasopharyngeal carcinoma in China, 2014]. Zhonghua Zhong Liu Za Zhi. 2018;40(8):566-571. Chinese. doi:10.3760/cma.j.issn.0253-3766.20 18.08 .002

5. Khuhaprema T, Srivatanakul P, Attsara A, Sriplung H, Wiangnon H, Sumitsawan Y. Nasopharyngeal carcinoma. Cancer Thail. 2010;21: vii308.

6. Eu D, Loh T. Benign and malignant tumors of the nasopharynx. In: Flint P, Francis H, Haughey B, Lesperance M, editors. Cummings Otolaryngology-Head and Neck Surgery. 7th ed. Elsevier; 2020:1394-1397.

7. Ilhan O, Sener EC, Ozyar E. Outcome of abducens nerve paralysis in patients with nasopharyngeal carcinoma. Eur J Ophthalmol. 2002;12 (1):55-59.

8. Indudharan $\mathrm{R}$, Valuyeetham KA, Kannan $\mathrm{T}$, Sidek DS. Nasopharyngeal carcinoma: clinical trends. $J$ Laryngol Otol. 1997;111(8):724-729. doi:10.1017/s0022215100138460

9. Baharudin A, Shahid H, Shah J, Suhaimi SD, Zulkiflee S. A rare isolated Bilateral abducens nerve palsy in Nasopharyngeal Carcinoma (NPC). Int J Anesthesiol. 2006;1. doi:10.5580/19d5
10. Chi SL, Bhatti MT. The diagnostic dilemma of neuro-imaging in acute isolated sixth nerve palsy. Curr Opin Ophthalmol. 2009;20 (6):423-429. doi:10.1097/ICU.0b013e3283313c2f

11. Rego-Lorca D, Burgos-Blasco B, Hernandez-Garcia E, Domingo-Gordo B. Abducens palsy as first manifestation of a nasopharyngeal carcinoma. Oral Oncol. 2021;114:105079. doi:10.1016/j.oraloncology.2020.105079

12. Moster ML, Savino PJ, Sergott RC, Bosley TM, Schatz NJ. Isolated sixth-nerve palsies in younger adults. Arch Ophthalmol. 1984;102 (9):1328-1330. doi:10.1001/archopht.1984.01040031078029

13. Bendszus M, Beck A, Koltzenburg M, et al. MRI in isolated sixth nerve palsies. Neuroradiology. 2001;43(9):742-745. doi:10.1007/ s002340100572

14. Patel SV, Mutyala S, Leske DA, Hodge DO, Holmes JM. Incidence, associations, and evaluation of sixth nerve palsy using a population-based method. Ophthalmology. 2004;111(2):369-375. doi:10.1016/j.ophtha.2003.05.024

15. Richards BW, Jones FR Jr, Younge BR. Causes and prognosis in 4278 cases of paralysis of the oculomotor, trochlear, and abducens cranial nerves. Am J Ophthalmol. 1992;113(5):489-496. doi:10.1016/ s0002-9394(14)74718-x

16. Chou KL, Galetta SL, Liu GT, et al. Acute ocular motor mononeuropathies: prospective study of the roles of neuroimaging and clinical assessment. $J$ Neurol Sci. 2004;219(1-2):35-39. doi:10.1016/j. jns.2003.12.003

17. Bitoh S, Hasegawa H, Fujiwara M, Ohtsuki H, Furukawa Y. Nasopharyngeal malignancies causing abducens palsy. Neurol Med Chir (Tokyo). 1983;23(7):571-576. doi:10.2176/nmc.23.571

18. Aghdam KA, Zand A, Sanjari MS. Isolated unilateral sixth nerve palsy in a patient with nasopharyngeal carcinoma. ROM J Ophthalmol. 2019;63(4):375-378.

19. Thomas JE, Waltz AG. Neurological manifestations of nasopharyngeal malignant tumors. JAMA. 1965;192:95-98. doi:10.1001/ jama.1965.03080150025004

20. Batawi H, Micieli JA. Nasopharyngeal carcinoma presenting as a sixth nerve palsy and Horner's syndrome. BMJ Case Rep. 2019;12(10). doi:10.1136/bcr-2019-232291
International Medical Case Reports Journal

\section{Publish your work in this journal}

The International Medical Case Reports Journal is an international, peer-reviewed open-access journal publishing original case reports from all medical specialties. Previously unpublished medical posters are also accepted relating to any area of clinical or preclinical science. Submissions should not normally exceed 2,000 words or 4 published pages including figures, diagrams and references. The manuscript management system is completely online and includes a very quick and fair peer-review system, which is all easy to use. Visit http://www.dovepress.com/testimonials.php to read real quotes from published authors. 